\title{
La voz del Cervantes «creador» en el Quijote
}

\author{
Florencio Sevilla Arroyo*
}

Pocos temas cervantinos resultan tan complejos y atractivos como el de las voces de la novela - de sus autores y de sus narradores- en el Quijote. Y no sólo por el magnífico coro, multitudinario y polifónico, que nuestro «raro inventor» fue capaz de orquestar para entonar su relato, sino también por la atención crítica que se le ha dedicado y la diversidad de las explicaciones resultantes. Si Cervantes gustó de enmascarar ficticiamente su quehacer novelesco tras múltiples disfraces, delegando en ellos toda la responsabilidad de la historia y del relato, los estudiosos no han regateado esfuerzos encaminados a deslindar puntualmente la identidad y la participación de cada uno de los intervinientes en la confección final de la historia quijotesca, con las miras puestas en el desenmascaramiento del creador. Sin embargo, ninguno de los partícipes ficticios textualizados en la novela parece identificable con la voz creativa de Miguel de Cervantes; como si el libro no fuese con él y surgiese, realmente, de la algarabía de intervinientes que pulula por sus páginas. De resultas, la voz cervantina queda irrecuperablemente silenciada en la ficción por un sinfín de «instancias narradoras» y la historia del ingenioso hidalgo manchego ha de ser leída como reconstrucción multitudinaria de no se sabe cuántos artífices: primer autor, autor segundo, cronistas, Cide Hamete, traductor, editor, pluma, autor final, autor textualizado, narrador extradiegéticoheterodiegético, etc.

Pues bien, aun asumiendo tan deslumbrante juego de voces narrativas como inobjetable, ya que así lo quiso su artífice empírico, nos negamos a aceptar la ausencia de la voz creativa de Cervantes - del Cervantes creador-, en el Quijote, por muchas instancias ficticias que se le antepongan.

* Universidad Autónoma de Madrid. 
La apuesta novelesca asumida aquí por el viejo excautivo era demasiado grande, recia y aun descabellada - acaso «nunca imaginada de otro alguno», al par de los pensamientos del hidalgo-, como para soterrar textualmente su verdadero alcance experimental bajo tantos y tantos intrusos ficticios. Incluso, estamos convencidos de que el avezado novelista evidencia explícita e inequívocamente su voz creativa - renovadora y experimental - a lo largo y ancho de las dos partes del libro, así sea so capa de este seudoautor o de aquel seudonarrador ficticios.

El objetivo de estas páginas es, precisamente, rastrear e identificar su presencia explícita - la voz ficcionalizada del Cervantes creador-, entre la maraña de los intermediarios ficticios, a lo largo de toda la novela y calibrar el sentido y el alcance de sus intervenciones.

\section{AUTORES Y NARRADORES FICTICIOS}

En efecto - como es bien sabido-, en el Quijote se nos cuenta no sólo la supuesta «historia» del ingenioso hidalgo y caballero don Quijote de la Mancha, sino también la — digamos — «historia de esa historia» ${ }^{1}$. Esto es, además de referir las andanzas vividas por el hidalgo manchego y su paciente escudero, se nos relata el proceso de reconstrucción histórica de las mismas y su elaboración textual hasta desembocar en el libro. En principio, el recurso no es precisamente original y no pasa de simple recreación paródica de tópicos fácilmente rastreables tanto en la tradición caballeresca como en algunos títulos áureos: el «autor ficticio» y el «manuscrito encontrado» ${ }^{2}$. Pero sabemos

1. G. Haley nos lo explicó con mucha más precisión: «Paralela a la supuesta historia de las aventuras de Don Quijote [en] la novela de Cervantes se incluye otra historia suplementaria, con desarrollo autónomo y distinto reparto de autores. Esta es la historia de cómo las aventuras de Don Quijote llegaron a conocerse y transmitirse, con la información sobre los avatares de su existencia en viejos escritos, y sobre las etapas seguidas hasta llegar al libro de Cervantes» («El narrador en Don Quijote: el retablo de Maese Pedro», en El Quijote, ed. de G. Haley, Madrid: Taurus, 1984, pp. 269-270).

2. Para nuestro actual propósito, bastará con recordar lo esencial del asunto de la mano de S. Fernández Mosquera: «El origen de un autor ficticio moro tiene mucho que ver con la parodia de los libros de caballerías. Es indudablemente la chispa de su nacimiento en la obra de Cervantes. Y su caracterización debe mucho a estas novelas. Recordemos que Montalvo es el editor (como nosotros lo entendemos en el Quijote) del Amadís y Elisabad su autor primero y también de las Sergas de Esplandián; que Fristón es el sabio que escribió Don Belianís de Grecia (que también tiene traductor, el licenciado Jerónimo Fernández); el sabio Rey Artidoro El caballero de la Cruz junto al árabe Xartón; Alquife el Amadís de Grecia; Lirgandeo y Artemidoro Espejo de Príncipes y Cavalleros... En todas ellas se utiliza el tópico del autor ficticio - normalmente sabio nigromante - escritor de la historia en griego, caldeo, latín e incluso árabe (El caballero de la Cruz) como en el Quijote y, consecuentemente, la presencia de un traductor» («Los autores ficticios del Quijote», Anales Cervantinos, XXIV (1986), pp. 47-65; disponible en el Centro Virtual Cervantes: 〈http://cvc.cervantes. es/obref/quijote_antologia/mosquera.htm)). Pero no se olvide que el recurso es utilizado en muchos otros títulos áureos (el Orlando, de Ariosto; las Epístolas familiares, de Guevara; La Araucana, de Ercilla; las Guerras civiles de Granada, de Pérez de Hita; etc.), y en alguno de ellos de manera muy próxima a la cervantina, como bien estudió F. Márquez Villanueva (Fuentes literarias cervantinas, Madrid: Gredos, 1973, pp. 244-257). 
bien que cuando Cervantes asume un motivo literario, no se conforma nunca con la repetición servil sino que opta siempre por la recreación original y la renovación brillante. En este caso concreto, el locus heredado de la narrativa anterior, repetido anodinamente hasta la saciedad por unos y otros sin mayores consecuencias artísticas, se ve potenciado por nuestro artífice hasta desencadenar una auténtica y deslumbrante «babelia» de intervinientes, imposible de cuantificar numéricamente y —más importante — imposible de individualizar funcionalmente: la voz y el manuscrito del «sabio autor» ancestral se manejan ahora con tal destreza paródica y quedan mediatizados por tantos y tan escurridizos intermediarios, que al final no sabemos ni cuántos intervienen, ni quién habla en cada momento, ni qué papel desempeña cada uno... Tan sólo se salvaguarda la maestría cervantina y su destreza en el manejo de las voces de la novela, pues — como bien señaló el profesor E. C. Riley—.

«A nadie se le ocurre pensar ni por un momento que la responsabilidad de la ficción no corresponda al autor, pero el lector es llevado fácilmente a aceptar esa simulación - y, por consiguiente, la ficción - como tal ficción. Cervantes se cuida mucho de aclarar que se trata de una impostura e induce al lector a participar en el juego» ${ }^{3}$.

No extraña, entonces, que los estudiosos y especialistas se hayan afanado en la localización e identificación de tantos y tantos implicados en las tareas novelescas, procurando además deslindar puntualmente las funciones de cada uno de ellos ${ }^{4}$. Y ciertamente los resultados obtenidos hasta ahora no han defraudado, pues la relación de las instancias novelescas - cronistas, autores, traductores, narradores, editores... o como les queramos llamar-implicadas en la confección final de la historia quijotesca puede alcanzar, dependiendo de cada cual, el magnífico número de los 18, incluso sin rebasar el capítulo IX de la primera parte. Así se desprende, al menos, de la enumeración de «todo tipo de colaboradores» en la continuación de la anécdota interrumpida en I-VIII que elabora M. ${ }^{a}$ Stoopen en uno de los trabajos más detallados sobre el tema ${ }^{5}$ 1.- «yo inicial», 2.- «autor desta historia», 3.- «pluma de terceros»,

3. Son palabras tomadas de su conocida Teoría de la novela en Cervantes (vers. cast. de C. Sahagún, Madrid: Taurus, 1981 [3.a], p. 317) que, para estas cuestiones, conviene completar con su Introducción al «Quijote» (trad. E. Torner Montoya, Barcelona: Crítica, 1990; cap. 13, pp. 183 y ss., sobre todo).

4. Una relación pionera de los estudios fundamentales consagrados al tema puede encontrarse en el trabajo, ya mencionado, de Fernández Mosquera («Los autores ficticios del Quijote»), además de en muchos otros: J. M. Martín Morán, El Quijote en ciernes. Los descuidos de Cervantes y las fases de elaboración textual, Turín: Dell’Orso, 1990 (\$3.1, n. 143; que hemos manejado en copia electrónica enviada por el autor); J. Montero Reguera, El «Quijote» y la crítica contemporánea, Alcalá de

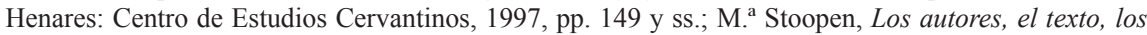
lectores en el «Quijote» de 1605, México: UNAM, 2002; etc. Aquí nos limitaremos a recoger sólo algunos, bien que procurando actualizar las referencias.

5. El que acabamos de mencionar en la nota anterior (Los autores..., pp. 242 y ss.). Naturalmente, luego reduce la cifra a la cantidad más o menos habitual: «Fungen, pues, como los sucesivos autores de la versión íntegra del texto, el autor explícito del prólogo y el amigo colaborador, el autor inicial de I, 1-8, el segundo autor, lector de la primera parte y del resto del libro, y Cide Hamete» (p. 282). 
4.- «segundo» autor, 5.- «ingenios de la Mancha», 6.- «sujeto narrativo», 7.- «lector del libro», 8.- «autor hipotético», 9.- «las gentes», 10.- «otros sabios», 11.- «escritor árabe», 12.- «traductor», 13.- «comentarista árabe», 14.- «vox populi», 15.- «pincel del pintor», 16.- «lector crítico», 17.- «autor oficial del Quijote» y 18.- «quién será aquel». Con carácter más general y mucho más recientemente, J. G. Maestro sistematiza las «diferentes instancias y procesos locutivos» detectables en el Quijote de 1605 como sigue (y nótese que rondan los 15$)^{6}$ :

1. Autor real: Miguel de Cervantes.

2. Autor «implícito» textualizado de forma discreta o discontinua en:

a) Autor primero: Anónimo (Caps. 1-8).

b) Cronista: Cide Hamete Benengeli (Cap. 9 en adelante).

c) Traductor: Morisco aljamiado.

d) Poetas: Académicos de Argamasilla.

e) Narrador: Voz textual anónima, que organiza, prologa y edita el texto completo.

3. Lector «implícito» textualizado de forma discreta y sincrética en:
a) Lector del texto del autor primero.
b) Lector de la crónica.
c) Lector de la traducción.
d) Lector de los poemas de los Académicos de Argamasilla.
e) Narratario.

4. Lector real: cualquiera de nosotros.

El profesor J. A. Parr, por su parte, venía ya insistiendo desde hace tiempo en varios trabajos ${ }^{7}$ sobre el número de voces narrativas, que llega a elevar a la cantidad de 10: 1.- autor inferido del conjunto de voces del texto, 2.- autor dramatizado de los prólogos, 3.- editor o supernarrador, 4.- autor histórico ficticio citado en el texto, 5.- narrador autónomo (del Curioso impertinente), 6.- científico de I, I-VIII, 7.- traductor, 8.- Cide Hamete, 9.- segundo autor, 10.- pluma. En fin, L. Gómez Canseco cree que en el libro se pueden detectar «hasta ocho relaciones distintas de la historia» ${ }^{8}$ :

1. Existencias reales de don Quijote y Sancho.

2. Primera versión imaginada por don Quijote en I-III.

3. Segunda versión recogida en la tradición oral y la documentación manchega.

4. Versión arábiga de Cide Hamete Benengeli.

6. En «Cide Hamete Benengeli y los narradores del Quijote» (〈http://www.cervantesvirtual. com)).

7. Los recuerda J. Montero en su libro ya citado (pp. 163-164). Entre ellos, destaca: An Anatomy of Subversive Discourse, Newark: Juan de la Cuesta, 1988.

8. Cfr. El «Quijote», de Miguel de Cervantes, Madrid: Síntesis, 2005, pp. 70-71. Bien es verdad que antes (pp. 62-63) había reducido a 6 la nómina de participantes en la elaboración del libro: 1.- Primer autor (I, I-VIII), 2.- Cide Hamete Benengeli, 3.- Traductor, 4.- Académicos de la Argamasilla, 5.- Autor del Curioso impertinente y 6.- Segundo autor [editor y padrastro]. 
5. Traducción al castellano del morisco.

6. Revisión y reescritura del segundo autor.

7. Alteraciones producidas por libreros y cajistas.

8. «Patraña pululante de Avellaneda».

No obstante, lo más habitual es no sobrepasar los 4 ó 5 , dependiendo de que se individualice e incluya o no al «autor definitivo», según concluyeron, hace ya mucho, Haley y Fernández Mosquera y suelen aceptar la mayoría de especialistas $^{9}$ :

1. El autor de los ocho primeros capítulos.

2. El editor.

3. El traductor.

4. Cide Hamete Benengeli.

5. El autor definitivo.

Pero, sean los que fueren «los autores que deste caso escriben» (I-I) ${ }^{10}$, luego vienen - para acabar de complicar las cosas - las precisiones y distingos sobre el papel (cronista-testigo de los hechos, investigador documental, traductor fidedigno, editor escrupuloso, etc.), las responsabilidades (veracidad histórica, fidelidad textual, continuidad del relato, etc.) y aun las tropelías de cada uno de ellos (ocultación de hechos, omisión de pasajes originales, intromisiones espurias, etc.). El enredo creativo es tan monumental como ingeniosas las exégesis y puntualizaciones críticas que ha provocado, si bien no entraremos, por ahora, ni en uno ni en otras, pues retomaremos la cuestión, más abajo, desde otro punto de vista.

9. El primero de ellos, en concreto, con un perspicaz planteamiento del entramado y reparto de funciones, extraído del «Retablo de maese Pedro», que vale la pena recordar: «El retablo de Maese Pedro es, pues, una analogía de la novela vista en su totalidad [...] porque reproduce en miniatura las relaciones fundamentales que se dan entre narrador, historia y público, según se aprecian en el esquema general de la obra» y «De igual modo lo es para Cervantes, quien, en vez de narrar por sí en su propio nombre, delega la función de autor de la supuesta historia en Cide Hamete, y, además, añade un traductor e intérpretes para declarar - traducir y narrar - la historia. La relación que guarda el autor-criminal Ginés de Pasamonte con el titiritero Maese Pedro, y éste a su vez con su ayudante, es, en lo esencial, la misma que se da entre Cervantes y el cronista Cide Hamete, y, de igual modo, entre éste y su traductor e intérpretes. Ginés de Pasamonte, el personaje histórico de su propia biografía, no figura en el reparto del retablo de Maese Pedro. Tampoco Cervantes se asigna a sí mismo una función explícita como autor de Don Quijote» (loc. cit., pp.. 285 y 283-284, respectivamente). El segundo, tan clara como expeditivamente: «Resumiendo: los autores ficticios del Quijote según nuestra propuesta son cinco: el autor de los ocho primeros capítulos, el editor, el traductor, Cide Hamete Benengeli y el autor definitivo» (loc. cit.).

10. Todos los pasajes del Quijote citados en estas páginas proceden de nuestra propia edición de la novela (Miguel de Cervantes, Obras completas, Madrid: Castalia, 1999) y se acompañarán sólo de la referencia a la parte y capítulo correspondientes, pues la difusión electrónica de la fuente permite su localización automática. 


\section{DISTANCIAMIENTO DEL CREADOR}

El hecho es - decimos - que, pese a la extraordinaria cantidad de instancias novelescas implicadas en el Quijote y a la deslumbrante riqueza de perfiles que ofrecen, absolutamente ninguna de ellas parece asumir la responsabilidad última del relato que leemos en sus páginas; nadie parece representar - adelantamosla «voz creativa» de nuestro novelista, pues ninguno de los participantes es identificable con Miguel de Cervantes ${ }^{11}$, aunque sólo sea porque así lo exige la más elemental convención literaria y porque es citado un par de veces como autor empírico desde el propio texto (como amigo del cura, en I-VI: «es grande amigo mío ese Cervantes», y como «un soldado español, llamado tal de Saavedra» en el relato de El cautivo, I-XL). De hecho, es éste, el propio autor real, quien gusta - decidido, acaso, a no sobrepasar el papel de padrastro que se asignara en el prólogo - de esconderse tras tales máscaras, delegando aparentemente toda la responsabilidad del relato - la creativa, la divulgativa y la enunciativa - en cuantas instancias narradoras ficticias ha sido capaz de inventar:

1. El «PADRASTRO» fingido del primer prólogo habrá de decidir si «sacar a luz las hazañas de tan noble caballero» o permitir «que el señor don Quijote se quede sepultado en sus archivos en la Mancha», así como deberá encargarse de redactar las piezas laudatorias preliminares e injerir alguna erudición tópica.

2. El NARRADOR INICIAL («En un lugar de la Mancha...», I-I) - ya se confunda con Cervantes, como suele hacerse; ya se identifique con Cide Hamete, como se desprende del final del libro: «Este fin tuvo el Ingenioso hidalgo de la Mancha, cuyo lugar no quiso poner Cide Hamete puntualmente» (II-LXXIV); o ya se individualice-, como autor y narrador de los ocho primeros capítulos que es, tendrá que reconstruir el arranque de la historia (lugar de nacimiento, nombre y forma de vida del protagonista, planteamiento del relato, etc.), basándose en rumores contradictorios y en otras supuestas versiones previas, aunque ello no le excusará de tomar decisiones sobre su desarrollo ni evitará que no pueda continuarla:

Quieren decir que tenía el sobrenombre de Quijada o Quesada, que en esto hay alguna diferencia en los autores que deste caso escriben; aunque, por conjeturas verosimiles, se deja entender que se llamaba Quejana [...] se vino a llamar don Quijote; de donde - como queda dicho- tomaron ocasión los autores desta tan verdadera historia que, sin duda, se debía de llamar Quijada, y no Quesada, como otros quisieron decir (I-I).

11. En ello hay casi unanimidad crítica, por lo que nos limitaremos a una sola referencia relativamente reciente: «Ciertamente Cervantes no es el narrador, nadie sabe quién es, solamente se puede afirmar que es un editor ficcional cuya historia se puede reconstruir en el texto hasta el límite en que el texto mismo lo permita [...]. Establecer quién es el narrador de Don Quijote, esto es, encontrar la identidad real del personaje que organiza la información en la obra, es una tarea imposible. Además, en este punto de la argumentación, la pregunta por la identidad de ese personaje no es relevante» (J. Quintero, «El narrador en Don Quijote: De la pregunta por su historia al descubrimiento de su función», Espéculo, 3 [2005], pp. 9-10). 
Autores hay que dicen que la primera aventura que le avino fue la del Puerto Lápice; otros dicen que la de los molinos de viento; pero, lo que yo he podido averiguar en este caso, y lo que he hallado escrito en los Anales de la Mancha, es que (I-II).

Y así, se cree que fueron al fuego, sin ser vistos ni oídos, La Carolea y León de España, con Los Hechos del Emperador, compuestos por don Luis de Ávila, que, sin duda, debían de estar entre los que quedaban; (I-VI).

En este punto y término deja pendiente el autor desta historia esta batalla, disculpándose que no halló más escrito destas hazañas de don Quijote de las que deja referidas (I-VIII).

3. Del SEGUNDO AUTOR, introducido al final de I-VIII como personaje más de la obra, a la vez que como relevo del anterior autor-lector - con independencia de que se le distinga o no del anterior y del papel global que se le asigne: editor ${ }^{12}$, supernarrador, autor definitivo, etc.del relato, interrumpido en la aventura del vizcaíno, siempre y cuando logre encontrar la fuente escrita de su continuación y, una vez hallada en el Alcaná de Toledo en caracteres árabes, consiga traducirla al romance castellano:

Bien es verdad que el segundo autor desta obra no quiso creer que tan curiosa historia estuviese entregada a las leyes del olvido, ni que hubiesen sido tan poco curiosos los ingenios de la Mancha que no tuviesen en sus archivos o en sus escritorios algunos papeles que deste famoso caballero tratasen; y así, con esta imaginación, no se desesperó de hallar el fin desta apacible historia, el cual, siéndole el cielo favorable, le halló del modo que se contará en la segunda parte (I-VIII).

Estando yo un día en el Alcaná de Toledo, llegó un muchacho a vender unos cartapacios y papeles viejos a un sedero [...] y vile con caracteres que conocí ser arábigos. Y, puesto que, aunque los conocía, no los sabía leer, anduve mirando si parecía por allí algún morisco aljamiado que los leyese [...] Cuando yo oí decir «Dulcinea del Toboso», quedé atónito y suspenso, porque luego se me representó que aquellos cartapacios contenían la historia de don Quijote. Con esta imaginación, le di priesa que leyese el principio y, haciéndolo ansí, volviendo de improviso el arábigo en castellano, dijo que decía: Historia de don Quijote de la Mancha, escrita por Cide Hamete Benengeli, historiador arábigo. [...] y roguéle me volviese aquellos cartapacios, todos los que trataban de don Quijote, en lengua castellana, sin quitarles ni añadirles nada, ofreciéndole la paga que él quisiese. Contentóse con dos arrobas de pasas y dos fanegas de trigo, y prometió de traducirlos bien y fielmente y con mucha brevedad. Pero yo, por facilitar más el negocio y por no dejar de la mano tan buen hallazgo, le truje a mi casa, donde en poco más de mes y medio la tradujo toda, del mesmo modo que aqui se refiere (I-IX).

12. Esa denominación le dan H. Percas de Ponseti (Cervantes y su concepto del arte. Estudio crítico de algunos aspectos y episodios del «Quijote», Madrid: Gredos, 1975, vol. I, p. 87) y Fernández Mosquera con particular convicción: «Editor porque se empeña en buscar lo que supone que falta, editor porque lo encuentra, manda traducir la historia y además paga por ello. Y probablemente es, también, el cristiano que se ocupó de mandarla imprimir» (loc. cit.). 
Además, salvado el escollo, queda a su cargo la narración definitiva de la historia, pues lo que al lector real le llega es su propia relación de la traducción hecha por el morisco del original de Cide Hamete: «En fin, su segunda parte, siguiendo la tradución, comenzaba desta manera» (I-IX).

4. En manos del TRADUCTOR estará, obviamente, la fidelidad de la versión castellana — según se le encarga y compromete: «sin quitarles ni añadirles nada [...] y prometió de traducirlos bien y fielmente» (I-IX) - al original árabe, que en un principio respeta con todo escrúpulo, sin descuidar ni siquiera las notas marginales ni los comentarios del autor, aunque no deja de tomarse ciertas licencias, bien omitiendo algún pasaje, bien añadiendo comentarios de su cosecha:

Dice el que tradujo esta grande historia del original, de la que escribió su primer autor Cide Hamete Benengeli, que, llegando al capítulo de la aventura de la cueva de Montesinos, en el margen dél estaban escritas, de mano del mesmo Hamete, estas mismas razones (II-XXIV).

Aquí pinta el autor todas las circunstancias de la casa de don Diego, [...] pero al traductor desta historia le pareció pasar estas y otras semejantes menudencias en silencio, porque no venían bien con el propósito principal de la historia (II-XVIII).

(Llegando a escribir el traductor desta historia este quinto capítulo, dice que le tiene por apócrifo, porque en él habla Sancho Panza con otro estilo del que se podía prometer de su corto ingenio (II-II).

5. Cide Hamete Benengeli, como supuesto testigo presencial de los hechos («dice Cide Hamete que pocas veces vio a Sancho Panza sin ver al rucio, ni al rucio sin ver a Sancho», II-XXXIV) y autor principal de la versión primera de la historia, será — por más que se quiera reducir a simple recurso paródico del motivo caballeresco y por mucho que se abulten las intromisiones del traductor y del editor- el máximo responsable de la novela entera; el artífice del texto base...:

Real y verdaderamente, todos los que gustan de semejantes historias como ésta deben de mostrarse agradecidos a Cide Hamete, su autor primero, por la curiosidad que tuvo en contarnos las semínimas della, sin dejar cosa, por menuda que fuese, que no la sacase a luz distintamente: pinta los pensamientos, descubre las imaginaciones, responde a las tácitas, aclara las dudas, resuelve los argumentos; finalmente, los átomos del más curioso deseo manifiesta (II-XL).

Tanto es así, que - llegado el caso - su autoría funcionará como marca inequívoca de autenticidad frente a la versión apócrifa de Avellaneda:

el Sancho y el don Quijote desa historia deben de ser otros que los que andan en aquella que compuso Cide Hamete Benengeli, que somos nosotros [...] y si fuera posible, se había de mandar que ninguno fuera osado a tratar de las cosas del gran don Quijote, si no fuese Cide Hamete, su primer autor (II-LIX).

Bien sea venido, digo, el valeroso don Quijote de la Mancha: no el falso, no el ficticio, no el apócrifo que en falsas historias estos días nos 
han mostrado, sino el verdadero, el legal y el fiel que nos describió Cide Hamete Benengeli, flor de los historiadores (II-LXI).

Y el diablo le respondió: «Ésta es la Segunda parte de la historia de don Quijote de la Mancha, no compuesta por Cide Hamete, su primer autor, sino por un aragonés, que él dice ser natural de Tordesillas» (II-LXXI).

y que el tal testimonio pedía para quitar la ocasión de algún otro autor que Cide Hamete Benengeli le resucitase falsamente (II-LXXIV).

En suma, Cervantes delega en él la configuración global de la «historia» a todos los niveles (historicidad y veracidad de los hechos, selección y organización de los sucesos incluidos, desarrollo del discurso, etc.), aunque no así - lógicamente - la que denominábamos «historia de la historia», encomendada a las demás instancias narrativas $\mathrm{y}$, particularmente, al editor.

6. El AUTOR DEFINITIVO, final, implícito, liminar, supernarrador, narrador extradiegético-heterodiegético... - o como buenamente alcancemos a denominarlo, pues de todas esas maneras y de muchas otras más se le ha llamadose alza como requisito imprescindible para que se sostenga, precisamente, tan complejo andamiaje autorial, pues de él depende, a la postre, la voz del último intermediario del relato - el más próximo al lector-o editor $\mathrm{y}$, de resultas, absolutamente todos los demás, como se desprende, por ejemplo, del cierre de I-VIII:

en este punto y término deja pendiente el autor desta historia esta batalla [...] Bien es verdad que el segundo autor desta obra [...] no se desesperó de hallar el fin desta apacible historia, el cual, siéndole el cielo favorable, le halló del modo que se contará en la segunda parte.

Por eso, quien más y quien menos acaba recurriendo a esa instancia superior (Haley, El Saffar, Fernández Mosquera, Paz Gago, Stoopen, etc.) ${ }^{13}$, inaprehensible e inidentificable en el texto por más que continuamente omnipresente, en cuyas manos está — suponemos - la orquestación de todo el coro de voces y, en suma, la factura literaria definitiva del Quijote.

7. Por cuenta de SANCHO PANZA, nada menos, correrá la restauración de ciertos «olvidos» cometidos en la primera parte — ya porque «el historiador

13. En los trabajos ya citados o recogidos en la bibliografía final. J. M. ${ }^{a}$ Paz Gago insiste particularmente en la necesidad de reconocer la existencia de un «narrador extradiegético-heterodiegético» cuyo papel define taxativamente: «La voz textual que asume y organiza el relato del Quijote, su configuración y estructuración, corresponde a un narrador extradiegético-heterodiegético, es decir, a una instancia narratorial situada en una posición exterior a la historia del Ingenioso Hidalgo Don Quijote de la Mancha y al universo ficcional en el que se desarrolla o diégesis [...]. Se trata del narrador que instaura la referencia al universo ficcional realista, la diégesis del relato que él mismo construye, manejando todo el sistema narrativo, actancial y ficcional, incluidos los autores ficticios» (Semiótica del "Quijote». Teoría y práctica de la ficción narrativa, Amsterdam-Atlanta: Rodopi, 1995 [Versión digital en 〈http://www.cervantesvirtual.com〉]). Claro que M. ${ }^{a}$ Stoopen lo corrige con no menos contundencia: «Es el autor implícito — y no sólo «la voz narrativa», como propone Paz Gago- quien está por encima de autores ficticios y narradores, la instancia que responde por la organización, el comportamiento y las intenciones textuales de unos y otros y maneja también el sistema actancial y ficcional» (Los autores, el texto..., p. 205). 
se engañó, o ya sería descuido del impresor» (II-IV)—, como, por ejemplo, los relativos al robo y la recuperación de su asno:

-A lo que el señor Sansón dijo que se deseaba saber quién, o cómo, o cuándo se me hurtó el jumento, respondiendo digo que la noche misma que, huyendo de la Santa Hermandad, nos entramos en Sierra Morena [...]. Al cabo de no sé cuántos días, viniendo con la señora princesa Micomicona, conocí mi asno, y que venía sobre él en hábito de gitano aquel Ginés de Pasamonte, aquel embustero y grandísimo maleador que quitamos mi señor y yo de la cadena (II-IV).

8. El LECTOR, en última instancia, se verá obligado a pronunciarse sobre la veracidad de algunos hechos relatados como históricos, aunque cuestionados desde la misma narración, como ocurre con los sucesos de la Cueva de Montesinos, «cuya imposibilidad y grandeza hace que se tenga esta aventura por apócrifa» (II-XXIII), en opinión del editor:

Tú, letor, pues eres prudente, juzga lo que te pareciere, que yo no debo ni puedo más; puesto que se tiene por cierto que al tiempo de su fin y muerte dicen que se retrató della, y dijo que él la había inventado, por parecerle que convenía y cuadraba bien con las aventuras que había leído en sus historias (II-XXIV).

9. En fin, a la mismísima PLUMA se le encomendará la misión crucial de zanjar para siempre la andanzas quijotescas anticipándose a cualquier intromisión apócrifa futura:

Para mí sola nació don Quijote, y yo para él; él supo obrar y yo escribir; solos los dos somos para en uno (II-LXXIV).

Y así ad libitum, sin posibilidad alguna de agotar la serie ${ }^{14}$ ni de acotar críticamente su riqueza artística, pues las cosas - los enredos, íbamos a decir - no acaban exactamente en tan inabarcable despliegue autorial ficticio, ni en tan notoria despreocupación por las responsabilidades narrativas. No conforme con tamaña mascarada ni con los papeles encomendados a cada marioneta, Cervantes les dispensa a todos ellos un tratamiento cómico irrisorio — ridículamente paródico, si se prefiere - que reduce a puro juego y divertimento lo que venimos denominando la «historia de la historia».

14. Piénsese, si no, en la FAMA («sólo la fama ha guardado, en las memorias de la Mancha, que don Quijote, la tercera vez que salió de su casa, fue a Zaragoza, donde se halló en unas famosas justas que en aquella ciudad hicieron, y allí le pasaron cosas dignas de su valor y buen entendimiento», I-LII); en el que bien podríamos llamar TRADUCTOR SEGUNDO, encargado de leer y pasar a limpio («los que se pudieron leer y sacar en limpio fueron los que aquí pone el fidedigno autor desta nueva y jamás vista historia», I-LII) los «diferentes epitafios y elogios» contenidos en los «pergaminos escritos con letras góticas» que se hallaron en la «caja de plomo» del «antiguo médico»; o en el ACADÉMICO que, supuestamente, logró declarar el resto del pergamino («Éstos fueron los versos que se pudieron leer; los demás, por estar carcomida la letra, se entregaron a un académico para que por conjeturas los declarase. Tiénese noticia que lo ha hecho, a costa de muchas vigilias y mucho trabajo, y que tiene intención de sacallos a luz, con esperanza de la tercera salida de don Quijote», I-LII); y eso, sin rebuscar demasiado en las «instancias narradoras» que todavía quedan en el tintero... 


\section{Planteamiento CÓMico}

Ciertamente, si las andanzas del caballero y su escudero son abiertamente ridículas, el esquema autorial y narrativo que las reconstruye y las relata no le va a la zaga en comicidad, se mire por donde se mire: desde la supuesta historicidad de los hechos referidos, hasta el diseño concreto de cada uno de los implicados en su reconstrucción tan puntual como veraz, todo es burla y mentira; todo ha sido pergeñado en clave humorística y, por eso mismo, admirablemente genial, como bien suele notar la crítica ${ }^{15}$. Aquí nos conformaremos con ilustrar algún que otro perfil de la burla y socarronería que informan a todas y cada una de las páginas de la novela de este punto de vista:

- Cide Hamete Benengeli, pese a ser el máximo responsable del grueso de tan puntual y magnífica historia — de ambas partes del Quijote, queremos decir - y el más sólido garante de su veracidad, está concebido y desarrollado - en consonancia con su función paródica del recurso caballeresco más arriba mencionado - como quintaesencia burlesca del sabio autor ficticio de dicha tradición. Su caracterización y funcionamiento no deja lugar a la más mínima duda:

Resulta que se trata de un autor «arábigo y manchego» (I-XXII) — que ya es decir-, además de «filósofo mahomético» (II-LIII), lo que pone de salida en entredicho su veracidad, pese a que acostumbre a jurar «como católico cristiano» (II-XXVII): «su autor era moro, según aquel nombre de Cide; y de los moros no se podía esperar verdad alguna, porque todos son embelecadores, falsarios y quimeristas» (II-III) y «Si a ésta se le puede poner alguna objeción cerca de su verdad, no podrá ser otra sino haber sido su autor arábigo, siendo muy propio de los de aquella nación ser mentirosos» (I-IX); pero es que además — para más señas—, parece ser pariente del arriero de Arévalo que pasa por la venta: «uno de los ricos arrieros de Arévalo, según lo dice el autor desta historia, que deste arriero hace particular mención, porque le conocía muy bien, y aun quieren decir que era algo pariente suyo» (I-XVI).

Aunque es historiador «sabio y atentado» (I-XXVII), con ribetes de encantador («debe de ser algún sabio encantador el autor de nuestra historia», II-II), y por tanto conocedor omnisciente de los más mínimos detalles («con otras cosas que pasamos nosotros a solas, que me hice cruces de espantado cómo las pudo saber el historiador que las escribió», II-II), así como puntilloso en extremo ( Fuera de que Cide Mahamate Benengeli fue historiador muy curioso y muy puntual en todas las cosas», I-XVI; «No se le quedó nada — respondió Sansón - al sabio en el tintero: todo lo dice y todo lo apunta», II-III; «Dice Cide Hamete, puntualísimo escudriñador de

15. Por ejemplo, Montero Reguera: «No creo que Cervantes se preocupara especialmente [...] por discernir claramente entre unos y otros narradores: se trataba de un juego que, a la vez, le permitía parodiar rasgos característicos de la novela de caballerías y distanciarse irónicamente él mismo de la narración, proporcionando mayor autonomía a sus propios personajes. [...] Pero lo que surgió en la mente de su creador como un juego no ha de convertirse en una interminable lista de posibles narradores que se puede aumentar con facilidad» (op. cit., p. 165). 
los átomos desta verdadera historia», II-L), luego resulta que pasa por alto las «más relevantes» puntualizaciones de la historia...: «venían tres labradoras sobre tres pollinos, o pollinas, que el autor no lo declara» (II-X), «le tomó la noche entre unas espesas encinas o alcornoques; que en esto no guarda la puntualidad Cide Hamete que en otras cosas suele» (II-LX), «Don Quijote, arrimado a un tronco de una haya o de un alcornoque - que Cide Hamete Benengeli no distingue el árbol que era» (II-LXVIII), etc.

- Las DOS PRIMERAS VOCES de los comienzos de la obra, aunque susceptibles de individualización en sus funciones narrativas (investigador/editor), comparten parejo afán en sacar a luz y divulgar la historia del insigne manchego («lo que yo he podido averiguar en este caso», I-II; «el trabajo y diligencia que puse en buscar el fin desta agradable historia», I-IX) y terminan desempeñando el triple papel de autores, narradores y lectores, según dejamos explicado más arriba. Ello, si no quedan definitivamente soterradas por la voz omnipresente de Cide Hamete Benegeli («cuyo lugar no quiso poner Cide Hamete», recuérdese).

- El TRADUCTOR morisco, tan respetuoso con el texto original como ya vimos — si acaso, un poco entrometido-, no deja de hacer su aparición en el ámbito autorial del relato con una carcajada incontenible, brindándonos una clave inequívoca del rumbo humorístico elegido:

En fin, la suerte me deparó uno, que, diciéndole mi deseo y poniéndole el libro en las manos, le abrió por medio y, leyendo un poco en él, se comenzó a reír.

Preguntéle yo que de qué se reía, y respondióme que de una cosa que tenía aquel libro escrita en el margen por anotación. Díjele que me la dijese; y él, sin dejar la risa, dijo:

-Está, como he dicho, aquí en el margen escrito esto: «Esta Dulcinea del Toboso, tantas veces en esta historia referida, dicen que tuvo la mejor mano para salar puercos que otra mujer de toda la Mancha» (I-IX).

Poco extraña que luego se explote esa veta cómica: «Llegando a escribir el traductor desta historia este quinto capítulo, dice que le tiene por apócrifo, porque en él habla Sancho Panza con otro estilo del que se podía prometer de su corto ingenio [...]; pero que no quiso dejar de traducirlo, por cumplir con lo que a su oficio debía» (II-V).

- El LECTOR, tendrá que sentenciar — decíamos - sobre la veracidad de algún pasaje, como el de la Cueva de Montesinos («juzga lo que te pareciere», II-XXIV), pero no se pase por alto que se le brindan varias apoyaturas «en verdad esclarecedoras»: a Cide Hamete le «parece apócrifa» (II-XXIV); los rumores «dicen que se retrató della, y dijo que él la había inventado» (II$\mathrm{XXIV})$; el mono adivino nada resuelve («El mono dice que parte de las cosas que vuesa merced vio, o pasó, en la dicha cueva son falsas, y parte verisímiles; y que esto es lo que sabe», II-XXV) y otro tanto ocurre con la respuesta de la cabeza encantada: «A lo de la cueva — respondieron - hay mucho que decir: de todo tiene» (II-LXXII); etc. 
- En fin, ya el PADRASTRO desde el prólogo - por no insistir en la socarronería del «gracioso y bien entendido» amigo - había anticipado la clave cómica del esquema autorial: «don Quijote de la Mancha, de quien hay opinión, por todos los habitadores del distrito del Campo de Montiel, que fue el más casto enamorado y el más valiente caballero que de muchos años a esta parte»...

La insistencia y continuidad con la que Cervantes mantiene semejante tratamiento burlesco del esquema autorial y narratológico a lo largo y ancho de toda la obra justifica cumplidamente - en otro orden de cosas - el gran número de solapamientos, entrecruzamientos y contradicciones observables en el manejo de tantos y tantos «colaboradores» ficticios, que - por lo demásterminan arrumbando la arquitectura narratológica del relato para reducirla a mera polvareda lúdica e ingeniosa... Sobre las irregularidades y demás despropósitos ya mencionados páginas arriba, saltan a la vista otros muchos pasajes sin solución de continuidad exegética alguna, se planteen como se planteen, como bien se ha hecho ver en alguna ocasión y aquí nos limitamos a mencionar:

- Si la voz anónima inicial está concebida con funciones de investigador, capaz de fijar su propia crónica, no se entiende que, repentinamente, se vea reducido a mero lector («no halló más escrito destas hazañas», I-VIII), como tampoco se explica su metamorfosis, o sustitución, por el «segundo autor desta obra» (I-VIII).

-El segundo autor, o editor — si es él quien habla —, pese a su empeño y desvelos por dar con la continuación de la historia quijotesca, termina conformándose con «que le den el mesmo crédito que suelen dar los discretos a los libros de caballerías, que tan validos andan en el mundo; que con esto se tendrá por bien pagado y satisfecho» (I-LII); esto es, no pide — como no podía ser de otro modo- «ningún crédito».

- Si Cide Hamete anota, de su misma mano, en el cartapacio arábigo original - tal y como testimonia el traductor al comienzo de II-XXIV-, que la aventura de la aventura de la Cueva de Montesinos «parece apócrifa», tal y cómo acabamos de leerla traducida de su propio texto, su credibilidad histórica se viene abajo e incluso se podría pensar en la existencia de otras versiones previas a las que no tiene acceso el traductor ni, en consecuencia, noticia alguna el editor.

- Tampoco es nada fácil de explicar, desde nuestro enfoque, el sentido y alcance de las conjeturas sobre si habrá segunda parte o no, tanteadas por Sansón Carrasco a la altura de II-IV («se duda que no ha de haber segunda parte»), y todavía menos la afirmación de Sancho: «Atienda ese señor moro, o lo que es, a mirar lo que hace; que yo y mi señor le daremos tanto ripio a la mano en materia de aventuras y de sucesos diferentes, que pueda componer no sólo segunda parte, sino ciento» (II-IV).

- Y no otra cosa ocurre con el solapamiento irresoluble de las voces de Cide Hamete y de Cervantes que cierra la novela - a vueltas con la pluma-, por más que se haya discutido — largo y tendido— sobre quién se sobrepone a 
quien ${ }^{16}$ : «y yo quedaré satisfecho y ufano de haber sido el primero que gozó el fruto de sus escritos enteramente, como deseaba, pues no ha sido otro mi deseo que poner en aborrecimiento de los hombres las fingidas y disparatadas historias de los libros de caballerías, que, por las de mi verdadero don Quijote, van ya tropezando, y han de caer del todo, sin duda alguna. Vale» (II-LXXIV).

- En fin, no dejan de incluirse pasajes intencionada y explícitamente enmarañados mucho más allá de la lógica, incluso de la más mínima coherencia, que se resisten a cualquier ensayo explicativo ni remotamente aceptable ${ }^{17}$ : por ejemplo, hemos de comulgar con que la tradición oral ha transmitido «de padres a hijos» ciertos pasajes, nada menos que del borrador original de Cide Hamete, que luego éste no incluyó en su texto árabigo definitivo, dejando a dos velas al traductor;

hay fama, por tradición de padres a hijos, que el autor desta verdadera historia hizo particulares capítulos della [amistad entre Rocinante y el rucio]; mas que, por guardar la decencia y decoro que a tan heroica historia se debe, no los puso en ella $[\ldots]$

Digo que dicen que dejó el autor escrito que los había comparado en la amistad a la que tuvieron Niso y Euríalo, y Pílades y Orestes (II-XII).

y por los mismos derroteros — cada vez más intrincados_-, resulta que «el propio original» arábigo de la historia contiene apreciaciones sobre los atropellos textuales cometidos por el traductor:

Dicen que en el propio original desta historia se lee que, llegando Cide Hamete a escribir este capítulo, no le tradujo su intérprete como él le había escrito, que fue un modo de queja que tuvo el moro de sí mismo, por haber tomado entre manos una historia tan seca y tan limitada como esta de don Quijote (II-XLIV).

16. Así lo explica Martín Morán: «Es decir, es más lógico pensar que Cide Hamete no suplanta al autor real sino que es éste quien, en la última frase de su obra, se apropia del discurso narrativo, aunque sin terminar de descubrirse del todo, para reafirmar lo que considera como el mensaje primordial de la novela. A consecuencia de esta legítima invasión los dos narradores, el árabe y el cristiano, se convierten en dos alteregos del autor, cuya única existencia posible es la ficticia, y cuya única entidad narrativa es la meramente discursiva; por eso Cervantes, elevando a Cide Hamete al nivel de la realidad extradiegética, puede disolverlos en la nada con un simple trazo de su pluma. [...] Las palabras finales de Cide Hamete a su pluma realizan la fusión completa de las instancias narrativas del relato; por eso mismo constituyen una prueba indiscutible de que tras los dos autores que hasta entonces han venido narrando las gestas de don Quijote se esconden otros tantos desdoblamientos de un narrador incógnito que, sin gran esfuerzo por nuestra parte, podemos identificar con el propio Cervantes» (loc. cit., §4.4).

17. Percas de Ponseti, refiriéndose al último pasaje que recogemos, observa: «Evidentemente, Cervantes quiere tal confusión y la imposibilidad de resolver la duda, aunque también quiere sugerir a un cuarto autor, creador del creador» (op. cit, vol. I, p. 95). Y Fernández Mosquera, en líneas más generales, afirma: «Pero es difícil explicar el desarrollo del recurso congruentemente. Existen algunas incoherencias dentro de la propia novela que impiden la articulación perfecta de tan complicado engranaje» (loc. cit.). 
Todo ello sumado - la multiplicación de instancias autoriales y narrativas, el distanciamiento buscado del autor empírico y, sobre todo, el abuso de la clave burlesca firmemente mantenida - justifica sobradamente - a nuestro entender - la necesidad inexcusable de admitir la omnipresencia de una voluntad creativa soberana - la del Cervantes creador o novelista- capaz de mover tan hábilmente los hilos del relato, pues sin su intervención omnipresente, el Quijote resulta, sencillamente, inexplicable. Una voluntad creativa que termina imponiéndose sobre tan nutrido coro de intervinientes y que, naturalmente, puede escucharse por boca de todos y cada uno de ellos, pues su artífice empírico, por mucho que se distancie de la historia y del lector, no está dispuesto — glosando palabras de El Saffar - a perder el control de su invención. Que Cervantes no figure en el reparto de tan magnífico montaje, no significa que no esté dirigiendo la escena ni que se esté privando de intervenir en la representación.

Sin embargo, no creemos que sea ese - el de manipular jocosamente el esquema autorial ficticio del relato - su cometido exclusivo y, mucho menos, el fundamental, como tampoco su explicación constituye el objetivo principal de nuestro acercamiento.

\section{LA VOZ DEL CREADOR}

Ocurre que, frente a esa sorna exuberante, cebada en la caricaturización de la «historia de la historia», que aparentemente descarga todo el peso de la novelización en las máscaras ficticias, hay una función narrativa de la que nuestro «raro inventor» no se mofa nunca ni tampoco confía jamás en manos de nadie. Se trata de la relación detallada y puntillosa de las circunstancias narrativas que concurren en las diferentes aventuras caballerescas de don Quijote y Sancho. Cuando se trata de asumir la invención, o la creación, del anecdotario seudocaballeresco que nutre la «historia» andantesca del viejo hidalgo lugareño, desaparecen radicalmente los juegos autoriales y las chanzas narratorias; se postergan — vale decir— las demás voces ficticias, para dejar vía libre a la voz decisiva del «autor final» o del «creador». En tales casos - decimos-, aflora y toma las riendas la voz del creador con una contundencia y firmeza capaz de sentenciar inequívocamente lo ocurrido en la historia; con una omnisciencia - convendría precisar - incluso anómala con nuestro novelista de por medio... Ahora no vale juguetear con las vacilaciones o desvaríos de los demás intervinientes ficticios (autores, cronistas, traductores, lectores...), pues todos quedan masivamente englobados y solapados por un narrador, o supernarrador, «omnisciente, omnipresente y omnipotente», como diría Paz Gago. Con independencia de quien esté creando, contando, traduciendo o relatando, acaba imponiéndose la voz y la perspectiva del creador primero con una solvencia inequívocamente cervantina. 
Esa es, precisamente - a nuestro entender-, la voz creativa del Cervantes novelista, plenamente entregado a la elaboración de su nueva propuesta experimental en el terreno narrativo: alumbrar una prosa literaria capaz de soldar indisolublemente lo histórico y lo poético, lo caballeresco y lo manchego, lo ficticio y lo prosaico, la vida y la literatura...; y esa es - dicho sea de pasola clave artística esencial del Quijote, según hemos sostenido en otro sitio y desde otro enfoque ${ }^{18}$.

Poco importa la aventura concreta a la que nos refiramos, pues se trata de un fenómeno omnipresente. Una vez superada la fase jocosa de los distingos autoriales, asoma siempre la voz del narrador definitivo - la enunciación ficcional del autor empírico, si se prefiere - con una autoridad, firmeza y rotundidad apabullantes, sin que importe lo más mínimo la instancia narrativa que esté en el uso de la palabra. Su seguridad es tan absoluta que disfruta de absoluta omnisciencia y puede, incluso, permitirse el lujo de juguetear con su propia perspectiva dosificando la información a su antojo: aquí se muestra «omnisciente», allí «poquisciente»; unas veces habla en primera persona, otras se pluraliza; ya resulta «infidente», ya «crítico», ya «irónico», ya «ubicuo»; etcétera. ${ }^{19}$.

Y no vaya a creerse que resulta difícil escuchar su voz en el Quijote. Muy al contrario, se deja oír nítidamente — decimos_-, a lo largo y ancho de toda la novela, cuando llega el momento de acotar con toda puntualidad las circunstancias narrativas de los sucesos supuestamente históricos, posibilitando así la fusión experimental perseguida. Oigámosle, aunque sólo sea mediante un muestreo fragmentario:

- Ya en la primera malandanza del buen hidalgo, la de las «mozas del partido» (I-II), que depende enteramente del primer autor anónimo del comienzo de la obra, se aprecia un marcado contraste entre la incertidumbre inicial (le cuesta Dios y ayuda reconstruir incluso los datos más elementales: nombre del protagonista, relaciones con Dulcinea, orden de las aventuras, etc.) y la omnisciencia con la que nos relata lo sucedido: no vacila en absoluto sobre las circunstancias concurrentes en la ficción realista («vio, no lejos del camino por donde iba, una venta [...] y llegó a ella a tiempo que anochecía»), de modo que puede graduar con toda exactitud - cual testigo visual - incluso el acercamiento («Fuese llegando a la venta [...] se llegó a la puerta de la venta [...] llegó a la venta y a las damas») y, por supuesto, conoce perfectamente

18. En «Miguel de Cervantes: realidad, ficción y verosimilitud», en Literatura Hispanoamericana del Siglo XX. Imaginación y fantasía, coord. G. Fernández Ariza, Málaga: Universidad de Málaga, 2004, pp. 91-128.

19. Son todos términos y distingos tomados de J. B. Avalle-Arce, quien considera evidente «que hay una clara experimentación con las voces del narrador, sin decidirse por ninguna. [...] Lo que se obtiene así es mantener el texto en estado de fluidez, y al lector en estado de inquieta participación en la gradual formulación novelística», para terminar concluyendo: «Vale decir que el narrador en Cervantes es un verdadero camaleón, que se adapta a las circunstancias del relato, o bien, cambiando la metáfora, se tornasola con la matización de los colores del arco iris» (Las novelas y sus narradores, Alcalá de Henares: Centro de Estudios Cervantinos, 2006, pp. 162 y 199, respectivamente). 
la vida y costumbres de los personajes, su catadura moral y pensamientos incluidos, claro está: «dos mujeres mozas, destas que llaman del partido, las cuales iban a Sevilla con unos arrieros que en la venta aquella noche acertaron a hacer jornada [...] se le representó que era un castillo [...] las dos destraídas mozas que allí estaban, que a él le parecieron dos hermosas doncellas o dos graciosas damas [...] Pensó el huésped que el haberle llamado castellano había sido por haberle parecido de los sanos de Castilla, aunque él era andaluz y de los de la playa de Sanlúcar, no menos ladrón que Caco, ni menos maleante que estudiantado paje». Claro que al final de tan chusco encuentro, el mismo narrador no acertará a referir los agradecimientos de don Quijote al huésped: «abrazando a su huésped, le dijo cosas tan estrañas, agradeciéndole la merced de haberle armado caballero, que no es posible acertar a referirlas» (II-III).

Y éste es sólo el primer exponente de lo que se generalizará a lo largo de toda la novela. Se diría que los episodios caballerescos -únicas vértebras de la historia quijotesca entera-, concebidos como tentativas experimentales autónomas encaminadas a fundir lo real con lo fantástico, corren siempre por cuenta del autor-narrador definitivo; de una instancia narrativa suprema que, por cierto, no reparará en transgresiones narratológicas con tal de lograr verosímilmente su descabellado objetivo; en este primer caso, fundir ventas con castillos, rameras con damas, venteros con castellanos, porqueros con enanos, arrieros con caballeros, etc. - que no es poco, ciertamente- Y es el caso que todo el libro prosigue - decimos - a ese tenor, intensificando incluso el modus operandi de tan magnífico y eficaz narrador, solo identificable con Cervantes $-\mathrm{o}$ con su voz ficcionalizada, vaya.

- En el encuentro también nocturno - por no perder el hilo- del caballero con Maritornes (I-XVI), ya de la mano, supuestamente, de Cide Hamete, del traductor o del segundo autor..., abundan las evidencias de la obsesión cervantina por escenificar los hechos con cuantas puntualizaciones sean precisas para garantizar - además de la parodia del correspondiente pasaje caballeresco, obvio es decirlo- la verosimilitud de la historia, para lo que no vacila en ceder la palabra al consabido supernarrador asfixiantemente sabelotodo:

Y, aunque era [la cama] de las enjalmas y mantas de sus machos, hacía mucha ventaja a la de don Quijote, que sólo contenía cuatro mal lisas tablas, sobre dos no muy iguales bancos, y un colchón que en lo sutil parecía colcha, lleno de bodoques, que, a no mostrar que eran de lana por algunas roturas, al tiento, en la dureza, semejaban de guijarro, y dos sábanas hechas de cuero de adarga, y una frazada, cuyos hilos, si se quisieran contar, no se perdiera uno solo de la cuenta [...]. Y cuéntase desta buena moza que jamás dio semejantes palabras que no las cumpliese, aunque las diese en un monte y sin testigo alguno [...]. Toda la venta estaba en silencio, y en toda ella no había otra luz que la que daba una lámpara que colgada en medio del portal ardía. Esta maravillosa quietud [...] le trujo a la imaginación una de las estrañas locuras que buenamente imaginarse pueden. Y fue que él se imaginó haber llegado a un famoso castillo [...]. Tentóle luego la camisa, y, aunque ella era de harpillera, a él le pareció ser de finísimo 
y delgado cendal. Traía en las muñecas unas cuentas de vidro, pero a él le dieron vislumbres de preciosas perlas orientales. Los cabellos, que en alguna manera tiraban a crines, él los marcó por hebras de lucidísimo oro de Arabia, cuyo resplandor al del mesmo sol escurecía. Y el aliento, que, sin duda alguna, olía a ensalada fiambre y trasnochada, a él le pareció que arrojaba de su boca un olor suave y aromático [...] y fue lo bueno que al ventero se le apagó el candil, y, como quedaron ascuras, dábanse tan sin compasión todos a bulto que, a doquiera que ponían la mano, no dejaban cosa sana $[\ldots]$.

Esto es, a nuestro sabio narrador no le importa en absoluto contarnos «a tientas» lo que está ocurriendo, pues la escena está a oscuras, pero no descuida ni el más mínimo detalle para que la grotesca confusión entre asturiana-camaranchón y princesa-castillo, con la subsiguiente gresca, resulten convincentes histórica y poéticamente.

Aquí el abuso es tan notorio que el propio Cervantes parece percatarse del mismo e intenta camuflarlo atribuyéndoselo explícitamente a Cide Hamete («Fuera de que Cide Mahamate Benengeli fue historiador muy curioso y muy puntual en todas las cosas; y échase bien de ver, pues las que quedan referidas, con ser tan mínimas y tan rateras, no las quiso pasar en silencio»), pero a renglón seguido queda notoriamente desenmascarado como único responsable: «Digo, pues, que después de haber visitado el arriero a su recua...».

- Pocos capítulos después, en I-XVIII, cuando la de los rebaños, sorprendemos a nuestro autor-creador-narrador dando una vuelta de tuerca más a sus estrategias narrativas, a la vez que exhibiendo su destreza novelesca para solapar verosímilmente rebaños y ejércitos sin otro auxilio ni técnica que la polvareda levantada por los primeros en los caminos manchegos. Ahora — dueño y señor de la situación-, retrasa sibilinamente la información objetiva, permitiendo que el lector comparta las vacilaciones y equívocos de los personajes, pero luego no duda en aseverar la verdad incontestablemente:

En estos coloquios iban don Quijote y su escudero, cuando vio don Quijote que por el camino que iban venía hacia ellos una grande y espesa polvareda; y, en viéndola, se volvió a Sancho y le dijo: «[...] ¿Ves aquella polvareda que allí se levanta, Sancho? Pues toda es cuajada de un copiosísimo ejército [...]». «A esa cuenta, dos deben de ser — dijo Sancho-, porque desta parte contraria se levanta asimesmo otra semejante polvareda». [...]. Y la polvareda que había visto la levantaban dos grandes manadas de ovejas y carneros que, por aquel mesmo camino, de dos diferentes partes venían, las cuales, con el polvo, no se echaron de ver hasta que llegaron cerca [...] Hiciéronlo ansí, y pusierónse sobre una loma, desde la cual se vieran bien las dos manadas que a don Quijote se le hicieron ejército, si las nubes del polvo que levantaban no les turbara y cegara la vista [...] «¿Cómo dices eso? —respondió don Quijote-. ¿No oyes el relinchar de los caballos, el tocar de los clarines, el ruido de los atambores?» «No oigo otra cosa - respondió Sancho- sino muchos balidos de ovejas y carneros». Y así era la verdad, porque ya llegaban cerca los dos rebaños... 
Nótese bien: «y así era la verdad», histórica y poética, por voluntad incontestable del creador, al pairo de las voces y aspavientos de los demás intervinientes ficticios en la fijación del relato.

- Más de lo mismo, en esencia - pero no sin las variaciones habituales - , nos ofrece la temerosa aventura de los batanes (I-XX), mantenida en suspensión hasta el desenlace mismo por una instancia narrativa que vuelve a consagrarse - de nuevo - a garantizar la verosimilitud poética de lo contado (confusión de los golpes de batán con una aventura fantástica sin otro recurso que la oscuridad y el ruido) para acabar pidiendo excusas al lector por la mismísima estrategia creativa:

[...] la escuridad de la noche no les dejaba ver cosa alguna; mas, no hubieron andado docientos pasos, cuando llegó a sus oídos un grande ruido de agua, como que de algunos grandes y levantados riscos se despeñaba. Alegróles el ruido en gran manera, $\mathrm{y}$, parándose a escuchar hacia qué parte sonaba, oyeron a deshora otro estruendo que les aguó el contento del agua [...]. Digo que oyeron que daban unos golpes a compás, con un cierto crujir de hierros y cadenas, que, acompañados del furioso estruendo del agua, que pusieran pavor a cualquier otro corazón que no fuera el de don Quijote. Era la noche, como se ha dicho, escura, y ellos acertaron a entrar entre unos árboles altos, cuyas hojas, movidas del blando viento, hacían un temeroso y manso ruido; de manera que la soledad, el sitio, la escuridad, el ruido del agua con el susurro de las hojas, todo causaba horror y espanto [...].

Otros cien pasos serían los que anduvieron, cuando, al doblar de una punta, pareció descubierta y patente la misma causa, sin que pudiese ser otra, de aquel horrísono y para ellos espantable ruido, que tan suspensos y medrosos toda la noche los había tenido. Y eran — si no lo has, joh lector!, por pesadumbre y enojo - seis mazos de batán, que con sus alternativos golpes aquel estruendo formaban.

Huelga insistir: «digo que», «era..., como se ha dicho», «sin que pudiese ser otra», «y eran»...

- Acaso la aventura del yelmo de Mambrino (I-XXI) represente la más clara muestra de cuanto venimos diciendo, aunque sólo sea porque en ella se alcanza uno de los mayores logros de toda la novela: la perfecta fusión de la realidad y la fantasía en el baciyelmo, imposible de atribuir a ninguna otra instancia narradora que no sea la del genial creador. A esta altura del relato, se detectan todas las maniobras del autor definitivo para identificar lo histórico con lo poético que venimos observando en otros pasajes:

—El comienzo ex nihilo, con una fórmula de apertura recurrente: «En esto, comenzó a llover un poco».

- El acercamiento progresivo a la ficción realista desde una óptica fantástica: «descubrió don Quijote un hombre a caballo [...] apenas le hubo visto [...] aquel caballero que hacia nosotros viene [...] desde media legua relumbraba [...] el pobre caballero llegaba cerca». 
— La complicidad del narrador con los equívocos quijotescos, o la presentación ambigua y juguetona de la realidad: «un hombre a caballo, que traía en la cabeza una cosa que relumbraba como si fuera de oro [...] trae sobre la cabeza una cosa que relumbra».

- En fin, la omnisciencia puntillosa y socarrona del creador o autor final, capaz de definir dogmáticamente la realidad ficcional manipulándola cuidadosamente («bacía de azófar [...] comenzó a llover [...] se puso la bacía sobre la cabeza; y, como estaba limpia, desde media legua relumbraba») para que bacía y yelmo pasen por la misma cosa:

Es, pues, el caso que el yelmo, y el caballo y caballero que don Quijote veía, era esto: que en aquel contorno había dos lugares, el uno tan pequeño, que ni tenía botica ni barbero, y el otro, que estaba junto a él, sí; y así, el barbero del mayor servía al menor, en el cual tuvo necesidad un enfermo de sangrarse y otro de hacerse la barba, para lo cual venía el barbero, y traía una bacía de azófar; y quiso la suerte que, al tiempo que venía, comenzó a llover, y, porque no se le manchase el sombrero, que debía de ser nuevo, se puso la bacía sobre la cabeza; y, como estaba limpia, desde media legua relumbraba. Venía sobre un asno pardo, como Sancho dijo, y ésta fue la ocasión que a don Quijote le pareció caballo rucio rodado, y caballero, y yelmo de oro; que todas las cosas que veía, con mucha facilidad las acomodaba a sus desvariadas caballerías y malandantes pensamientos.

Añádase a todo ello que, en este caso, incluso los usos gramaticales de quien narra denuncian la identidad creativa de su voz: «Mandó a Sancho que alzase el yelmo, el cual, tomándola en las manos».

- La descomunal pelea con los cueros de vino tinto (I-XXXV) responde, lógicamente, a la misma mecánica creativa y es narrada por la misma voz, si bien ahora el supernarrador deja que sean Sancho y el ventero quienes presenten y expliquen, en primer lugar, el solapamiento perseguido (vino tinto de los cueros y sangre del gigante),

socorred a mi señor, [...] que ha dado una cuchillada al gigante enemigo de la señora princesa Micomicona, que le ha tajado la cabeza, cercen a cercen, como si fuera un nabo [...], que yo vi correr la sangre por el suelo, y la cabeza cortada y caída a un lado, que es tamaña como un gran cuero de vino. «Que me maten — dijo a esta sazón el ventero — si don Quijote, o don diablo, no ha dado alguna cuchillada en alguno de los cueros de vino tinto que a su cabecera estaban llenos, y el vino derramado debe de ser lo que le parece sangre a este buen hombre». [...] Andaba Sancho buscando la cabeza del gigante por todo el suelo [...] «y ahora no parece por aquí esta cabeza que vi cortar por mis mismísimos ojos, y la sangre corría del cuerpo como de una fuente». «¿Qué sangre ni qué fuente dices, enemigo de Dios y de sus santos? — dijo el ventero-. ¿No vees, ladrón, que la sangre y la fuente no es otra cosa que estos cueros que aquí están horadados y el vino tinto que nada en este aposento...?». 
para entrar él en acción después y enseñarnos sus cartas con la prolijidad machacona de siempre:

\begin{abstract}
Y, con esto, entró en el aposento, y todos tras él, y hallaron a don Quijote en el más estraño traje del mundo: estaba en camisa, la cual no era tan cumplida que por delante le acabase de cubrir los muslos, y por detrás tenía seis dedos menos; las piernas eran muy largas y flacas, llenas de vello y no nada limpias; tenía en la cabeza un bonetillo colorado, grasiento, que era del ventero; en el brazo izquierdo tenía revuelta la manta de la cama, con quien tenía ojeriza Sancho, y él se sabía bien el porqué; y en la derecha, desenvainada la espada, con la cual daba cuchilladas a todas partes, diciendo palabras como si verdaderamente estuviera peleando con algún gigante. $\mathrm{Y}$ es lo bueno que no tenía los ojos abiertos, porque estaba durmiendo y soñando que estaba en batalla con el gigante; que fue tan intensa la imaginación de la aventura que iba a fenecer, que le hizo soñar que ya había llegado al reino de Micomicón, y que ya estaba en la pelea con su enemigo. Y había dado tantas cuchilladas en los cueros, creyendo que las daba en el gigante, que todo el aposento estaba lleno de vino.
\end{abstract}

Se apreciará que la intromisión del autor final aquí es notoriamente innecesaria y aún redundante («había dado tantas cuchilladas en los cueros, creyendo que las daba en el gigante, que todo el aposento estaba lleno de vino», repite una y otra vez), enmarcada como está por dos diálogos entre Sancho y el ventero que han descrito y justificado cabalmente el equívoco protagonizado por don Quijote. Sin embargo, no por eso es gratuita ni impertinente: gracias a sus puntualizaciones, lo que no pasaba de disparate absurdo (la confusión de un cuero de vino con un gigantazo) se convierte en confusión verosímil: simplemente, don Quijote «estaba durmiendo y soñando [...] que ya estaba en la pelea con su enemigo»y, naturalmente, los sueños de los personajes les están vetados a los demás narradores; son propiedad exclusiva de la voz de su amo.

- Incluso el descenso de don Quijote a la cueva de Montesinos (II, XXIIXXIII) — por no limitarnos a la primera parte — se nos antoja cortado, pese a su extraordinaria elaboración artística en tantos sentidos y a su peso específico dentro de la novela, con el mismo patrón que los demás pasajes caballerescos, al menos desde un punto de vista narrativo. Nuestro artífice encuadra la escena con toda suerte de pormenores, encaminados a garantizar su eficacia novelesca en los dos planos que más le interesan: la comicidad y la verosimilitud. Por eso precisamente se abstiene muy mucho de contar, y aun de explicar - como suele hacer- la estupenda visión del caballero y deja que sea él mismo quien la relate: aún filtrada por el sueño, es demasiado arriesgada novelísticamente para nuestro avezado creador, pues consiste en apostar por la realidad contante y sonante de los sueños («y vi que no dormía, sino que realmente estaba despierto; con todo esto, me tenté la cabeza y los pechos, por certificarme si era yo mismo el que allí estaba, o alguna fantasma vana y contrahecha; pero el tacto, el sentimiento, los discursos concertados que entre 
mí hacía, me certificaron que yo era allí entonces el que soy aquí ahora») y no está dispuesto a llegar tan lejos — como tampoco se atreverá a desencantar a Dulcinea-; se limita a dejar bien clarito que don Quijote se ha dormido y, en consecuencia, se ha inventado, o soñado, todo lo que cuenta:

compraron casi cien brazas de soga, y otro día, a las dos de la tarde, llegaron a la cueva, cuya boca es espaciosa y ancha, pero llena de cambroneras y cabrahígos, de zarzas y malezas, tan espesas y intricadas, que de todo en todo la ciegan y encubren [...] comenzó a derribar y a cortar de aquellas malezas que a la boca de la cueva estaban, por cuyo ruido y estruendo salieron por ella una infinidad de grandísimos cuervos y grajos, tan espesos y con tanta priesa, que dieron con don Quijote en el suelo [...] ya ellos tenían descolgadas las cien brazas de soga, y fueron de parecer de volver a subir a don Quijote, pues no le podían dar más cuerda. Con todo eso, se detuvieron como media hora, [...] a poco más de las ochenta brazas, sintieron peso, de que en estremo se alegraron. Finalmente, a las diez vieron distintamente a don Quijote [...]. Pero no respondía palabra don Quijote; y, sacándole del todo, vieron que traía cerrados los ojos, con muestras de estar dormido. Tendiéronle en el suelo y desliáronle, y con todo esto no despertaba; [...] volvió en sí, desperezándose, bien como si de algún grave y profundo sueño despertara (I-XXIII).

El mayor logro y acierto en este caso, además de la mejor prueba de la identidad suprema de quien narra, consiste — desde nuestro enfoque - en involucrar en la cuestión tanto al narrador ficticio principal, Cide Hamete, como al lector en general: al primero, para que tache de apócrifa la relación del hidalgo y asuma la responsabilidad de su escritura («si esta aventura parece apócrifa, yo no tengo la culpa; y así, sin afirmarla por falsa o verdadera, la escribo», I-XXIV); al segundo, para que se pronuncie definitivamente sobre su historicidad y verismo («Tú, letor, pues eres prudente, juzga lo que te pareciere, que yo no debo ni puedo más»). En todo caso, el único culpable posible de todo el embrollo, el creador, el narrador final o - más a las claras- Cervantes, se lava las manos bonitamente...; mayor virtuosismo, imposible.

- La aventura del barco encantado (II-XXIX), como ejemplo más, es un verdadero calco narratológico de la de los molinos de viento (I-VIII) y, por tanto, una buena prueba de que Cervantes sigue trabajando en la misma línea diez años después de la aparición de su novela. Volvemos a encontrarnos con un nuevo bloque caballeresco («Yendo, pues, desta manera...») enteramente asumido por el narrador supremo con la mecánica e intereses narrativos de siempre:

Yendo, pues, desta manera, se le ofreció a la vista un pequeño barco sin remos ni otras jarcias algunas, que estaba atado en la orilla a un tronco de un árbol que en la ribera estaba. [...] En esto, descubrieron unas grandes aceñas que en la mitad del río estaban; y apenas las hubo visto don Quijote, cuando con voz alta dijo a Sancho: «¿Vees? Allí, joh amigo!, se descubre la ciudad, castillo o fortaleza donde debe de estar algún caballero oprimido, 
o alguna reina, infanta o princesa malparada, para cuyo socorro soy aquí traído». "¿Qué diablos de ciudad, fortaleza o castillo dice vuesa merced, señor? - dijo Sancho- ¿. ¿No echa de ver que aquéllas son aceñas que están en el río, donde se muele el trigo?». [...] En esto, el barco, entrado en la mitad de la corriente del río, comenzó a caminar no tan lentamente como hasta allí. Los molineros de las aceñas, que vieron venir aquel barco por el río, y que se iba a embocar por el raudal de las ruedas, salieron con presteza muchos dellos con varas largas a detenerle, y, como salían enharinados, y cubiertos los rostros y los vestidos del polvo de la harina, representaban una mala vista.

Obviamente, lo que enriquece ahora el cuadro es la magnífica e irrisoria aproximación, por vía de «encantamento», a la fortaleza-aceña.

- Pues hemos de cortar en algún sitio, la aventura de Clavileño (II-XLI) nos servirá para cerrar esta serie de ejemplos, que bien podría alargarse hasta abarcar la totalidad de los dos Quijotes. Como era de esperar tras lo visto, nuestro agente narrativo principal sigue en guardia, aunque escudado tras la máscara de Cide Hamete - acaba de elogiar su omnisciencia y meticulosidad al comienzo de II-XL_- aplicando su modus operandi de siempre. Elige, una vez más, el anochecer para dar inicio a la acción («Llegó en esto la noche [...] cuando a deshora entraron por el jardín cuatro salvajes, vestidos todos de verde yedra, que sobre sus hombros traían un gran caballo de madera»), que no deja de salpimentar con una buena dosis de humor («no parecía sino figura de tapiz flamenco pintada o tejida en algún romano triunfo. [...] pidió al duque que, si fuese posible, le acomodasen de algún cojín o de alguna almohada [...] porque las ancas de aquel caballo más parecían de mármol que de leño [...] lo que podía hacer era ponerse a mujeriegas»), para centrarse en la justificación verosímil y omnisciente de tan disparatada «volatería»:

Hízolo así Sancho, y, diciendo «a Dios», se dejó vendar los ojos [...]. Cubriéronse [...]. Y así era ello, que unos grandes fuelles le estaban haciendo aire: tan bien trazada estaba la tal aventura por el duque y la duquesa y su mayordomo, que no le faltó requisito que la dejase de hacer perfecta. [...]. En esto, con unas estopas ligeras de encenderse y apagarse, desde lejos, pendientes de una caña, les calentaban los rostros [...]. Todas estas pláticas de los dos valientes oían el duque y la duquesa y los del jardín, de que recibían estraordinario contento; y, queriendo dar remate a la estraña y bien fabricada aventura, por la cola de Clavileño le pegaron fuego con unas estopas, y al punto, por estar el caballo lleno de cohetes tronadores, voló por los aires, con estraño ruido, y dio con don Quijote y con Sancho Panza en el suelo, medio chamuscados.

Lo bueno del caso está ahora en la maestría y confianza en sus procedimientos que ha adquirido el creador-narrador primero, pues se atreve incluso a permitir que sus personajes cuestionen y casi casi descubran sus artimañas verosimilizadoras: 
«Señor, ¿cómo dicen éstos que vamos tan altos, si alcanzan acá sus voces, y no parecen sino que están aquí hablando junto a nosotros?» [...] «en todos los días de mi vida he subido en cabalgadura de paso más llano: no parece sino que no nos movemos de un lugar» [...] «que parece que con mil fuelles me están soplando».

Luego, dejará clarísimo quien está orquestando el tinglado, cuando remite - en singular pirueta novelesca - a la engañifa de la cueva de Montesinos: «Sancho, pues vos queréis que se os crea lo que habéis visto en el cielo, yo quiero que vos me creáis a mí lo que vi en la cueva de Montesinos; y no os digo más».

Poco costaría seguir acarreando casos y ejemplos de las páginas quijotescas para engrosar esta galería, pero el resultado final en nada se alteraría, pues estamos ante una constante que recorre la novela de principio a fin (frailes benitos, I-VIII; cuerpo muerto, I-XIX; disciplinantes, I-LII; cortes de la muerte, II-XI; espanto gatuno, II-XLVI; etc.): la omnipresencia de una instancia narrativa superior — sin que importe cómo la denominemos ni su identidad empírica - consagrada a generar un nuevo territorio novelesco ubicado en la intersección verosímil entre la realidad más prosaica y la ficción más disparatada ${ }^{20}$. Quien habla por ese canal, que termina oyéndose mucho más que ningún otro, no lo hace como historiador, ni como cronista, ni como encantador, ni como editor, ni como traductor, ni como lector...; lo hace, exclusivamente, como creador con todas las letras y consecuencias. Está inventando lo que cuenta y por eso se comporta - muy por encima de las demás voces ficticias - plenipotenciariamente: es omnisciente al cien por cien, es guasón como él solo, es escurridizo a más no poder, es ubicuo si hace falta, es poliédrico gramaticalmente..., es Miguel de Cervantes Saavedra, capaz de elaborar la novela por excelencia sin más utillaje que la oscuridad de la noche, el viento de los campos, el polvo de los caminos, la lluvia a campo abierto, la ensoñación visionaria, la harina de las aceñas, etc. ${ }^{21}$.

20. Otra cuestión, todavía más interesante — que aquí no cabe ni siquiera plantear-, sería intentar formalizar y sistematizar tanto el modus operandi enunciativo de esa instancia como su posible evolución a lo largo de la obra. Tomamos nota, no obstante, del planteamiento de Martín Morán, que distingue hasta tres «versiones [del] sistema enunciativo» - en consecuencia con las tres salidas del caballero-, cada una de las cuales «instaura un nuevo pacto narrativo con el lector: preterición de la veracidad de lo narrado para dar paso al argumento de autoridad fehaciente, en el primer sistema; reconocimiento del carácter ficticio de lo narrado [...], en el segundo sistema; reclamación de la genuidad de la historia, no de su veracidad [...], en la tercera». («Reunión de narradores, autor muerto. Los tres sistemas enunciativos del Quijote», en Releyendo el Quijote, cuatrocientos años después, dir. A. Redondo, Alcalá de Henares: Centro de Estudios Cervantinos-Presses de la Sorbonne Nouvelle, 2005, pp. 159-173; en concreto, 170).

21. Desafortunadamente, también hemos de dejar pendiente, por ahora, la posible organicidad estructural de tan lograda serie de modos de presentación que el profesor Riley consideraba dispuestos -nos parece que simplificando un tanto lo que dejamos expuesto más arriba- «en tres fases distintas» (1. ${ }^{\mathrm{a}}$ I, I-XVII: el narrador comienza informándonos objetivamente de la realidad; 2 . $^{\mathrm{a}} \mathrm{I}$, XVIII-LII: se retrasa la presentación objetiva, aproximando las posturas de don Quijote y del lector; 3. ${ }^{a}$ II, y en especial IX-XXX: el narrador participa de la confusión de sus héroes), que responderían a cierta progresión evolutiva: «Hemos visto pasar al narrador de una posición relativamente dominante de 


\section{CIERRE}

En suma, atando cabos, creemos que en el Quijote conviene diferenciar nítidamente tanto el papel autorial que Miguel de Cervantes se reserva como el tratamiento que dispensa a los materiales del relato, según se trate de la que hemos denominado «historia de la historia» o de la «historia» en sí misma, aunque en ambos casos deja oír su propia voz ficcional, de creador, en el texto. Tratándose de la primera — puro y simple cascarón huero, desarrollado a partir de la tópica caballeresca: sabio autor y manuscrito encontrado-, se queda fuera del reparto, delegando todas las tareas de reconstrucción en múltiples máscaras ficticias, que luego manipula cómicamente, desde la sombra y la impunidad de la mano negra, hasta reducirlas a puro juego de ingenio: una colosal babelia de todo punto inextricable. Cuando le toca el turno a la segunda - singular tentativa experimental de lograr una prosa literaria de rabiosa novedad, a caballo entre lo histórico y lo poético-, también permanece agazapado y oculto tras sus máscaras ficticias, pero ahora, en cambio, asume su empresa creativa — sin mermarle por ello comicidad - con absoluta seriedad y compromiso, usurpando descaradamente el uso de la palabra a las demás entelequias para imponer la suya: la voz del creador de la novela moderna. El Quijote resultante sólo puede ser explicado desde la intersección de ambos componentes y comportamientos: la historia risible de la más grave y grandiosa apuesta novelesca nunca ensayada.

\section{BIBLIOGRAFÍA}

Allen, J. J. (1976), «The Narrators, the Reader and Don Quijote», Modern Language Notes, 91 (1976), pp. 201-212.

Avalle-ArCe, J. B. de, Las novelas y sus narradores, Alcalá de Henares, Centro de Estudios Cervantinos, 2006.

Blasco Pascual, J., Cervantes, raro inventor, México, Universidad de Guanajuato, 1998 (y Alcalá de Henares, Centro de Estudios Cervantinos, 2005).

Blasco Pascual, J., Miguel de Cervantes Saavedra, regocijo de las musas, Valladolid, Universidad de Valladolid, 2005.

Castro, A., «El cómo y el porqué de Cide Hamete Benengeli», en Hacia Cervantes, Madrid, Taurus, 1967 (3. $\left.{ }^{\mathrm{a}}\right)$, pp. 409-419.

Castro, A., El pensamiento de Cervantes, Madrid, C.E.H., 1925 (y nueva ed. con notas de J. Rodríguez Puértolas, Barcelona-Madrid, Noguer, 1972 y 1980).

EISENBERG, D., «The Pseudo-Historicity of Romances of Chivalry», en Romances of Chivalry in the Spanish Golden Age, Newark, Juan de la Cuesta Hispanic Monographs, 1982.

El Saffar, R. S., «La función del narrador ficticio en Don Quijote», trad. de M. Juliá y G. Reyes, en El Quijote, ed. de G. Haley, Madrid, Taurus, 1984, pp. 288-299.

omnisciencia a lo que es casi una identificación con el punto de vista de don Quijote» (Introducción, pp. 183-191). Claro que ahí están los «batanes» (I-XX) o las «aceñas» (II-XXIX), sin ir más lejos, para invertir cabalmente la propuesta, echando por tierra cualquier intento de sistematización. 
El SAfFar, R. S., Distance and Control in Don Quixote. A Study in Narrative Technique, North Carolina Studies in the Romances Languages and Literatures, Chapel Hill, University of North Carolina Press, 1975.

Fernández Mosquera, S., «Los autores ficticios del Quijote», Anales Cervantinos, XXIV (1986), pp. 47-65.

Flores, R. M., «The Role of Cide Hamete en Don Quixote», Bulletin of Hispanic Studies, 59 (1982), pp. 3-14.

Gómez Canseco, L., El «Quijote», de Miguel de Cervantes, Madrid, Síntesis, 2005.

Haley, G., «El narrador en Don Quijote: el retablo de Maese Pedro», en El Quijote, ed. de G. Haley, Madrid, Taurus, 1984, pp. 269-287.

HALEY, G., «The narrator in Don Quixote: a discarded Voice», Estudios en honor a Ricardo Gullón, pp. 173-183.

LATHrop, Th. A., "Cide Hamete Benengeli y su manuscrito», en Cervantes: su obra y su mundo. Actas del I Congreso Internacional sobre Cervantes, Madrid, Edi-6, 1981, pp. 693-697.

Lázaro Carreter, F., «Las voces del Quijote», en Miguel de Cervantes, Don Quijote de la Mancha, ed. de F. Rico, Barcelona: Instituto Cervantes-Crítica, 1998, vol. I, pp. XXI-XXXVII.

LÓPEZ NAVIA, S. A., «Sabio, autor e historiador. Categorías atributivas y paralelas a Cide Hamete Benengeli en el texto del Quijote», en J. M. Casasayas (ed.), Actas del I Coloquio Internacional de la Asociación de Cervantistas, Barcelona, Anthropos, 1990, pp. 211-222).

Maestro, J. G., «El sistema narrativo del Quijote: la construcción del personaje Cide Hamete Benengeli», Cervantes, XV-1 (1995), pp. 111-141.

Maestro, J. G., «Cide Hamete Benengeli y los narradores del Quijote», BVMCS.

MÁRquez Villanueva, F., Fuentes literarias cervantinas, Madrid, Gredos, 1973, pp. 244257.

Martín Morán, J. M., «La construcción del personaje en el Quijote y el Guzmán», Criticón, 101 (2007), pp. 89-107.

Martín Morán, J. M., «La función del narrador múltiple en el Quijote de 1615», Anales Cervantinos, 30 (1992), pp. 9-65.

Martín Morán, J. M., El Quijote en ciernes. Los descuidos de Cervantes y las fases de elaboración textual, Turín, Dell’Orso, 1990.

MARTín MorÁN, J. M., «Reunión de narradores, autor muerto. Los tres sistemas enunciativos del Quijote», en Releyendo el Quijote, cuatrocientos años después, dir. A. Redondo, Alcalá de Henares, Centro de Estudios Cervantinos-Presses de la Sorbonne Nouvelle, 2005, pp. 159-173.

Molho, M., «Instancias narradoras en Don Quijote», MLN, 104-2 (1989), pp. 273-285.

Montero Reguera, J., El "Quijote» y la crítica contemporánea, Alcalá de Henares: Centro de Estudios Cervantinos, 1997.

Nepaulsingh, C. I., "La aventura de los narradores del Quijote», en Actas del VI Congreso Internacional de Hispanistas, Toronto, Department of Spanish and Portuguese, University of Toronto, 1980, pp. 515-518.

PARR, J. A., An Anatomy of Subversive Discourse, Newark, Juan de la Cuesta, 1988.

Paz Gago, J. M. ', Semiótica del "Quijote». Teoría y práctica de la ficción narrativa, Amsterdam-Atlanta, Rodopi, 1995 [Versión digital en BVMCS].

Percas de Ponseti, H., Cervantes y su concepto del arte. Estudio crítico de algunos aspectos y episodios del «Quijote», Madrid, Gredos, 1975 (2 vols.).

Quintero, J., «El narrador en Don Quijote: De la pregunta por su historia al descubrimiento de su función», Espéculo, 3 (2005). 
Redondo, A., Otra manera de leer el «Quijote», Madrid, Castalia, 1997.

Rey Hazas, A., Poética de la libertad y otras claves cervantinas, Madrid, Ediciones Eneida, 2005.

RiLey, E. C., Teoría de la novela en Cervantes, vers. cast. de C. Sahagún, Madrid, Taurus, $1981\left(3 .{ }^{a}\right)$.

Riley, E. C., Introducción al «Quijote», trad. E. Torner Montoya, Barcelona, Crítica, 1990.

RiLEY, E. C., La rara invención. Estudios sobre Cervantes y su posteridad literaria, Barcelona, Crítica, 2001.

Sevilla Arroyo, F., «Miguel de Cervantes: realidad, ficción y verosimilitud», Literatura Hispanoamericana del Siglo XX. Imaginación y fantasía, coord. G. Fernández Ariza, Málaga, Universidad de Málaga, 2004, pp. 91-128.

SPITZER, L., «Perspectivismo lingüístico en El Quijote», en Lingüística e historia literaria, Madrid: Gredos, 1974 (2. $\left.{ }^{\mathrm{a}}\right)$, pp. 135-187.

StOOPEN, M. ${ }^{\mathrm{a}}$, Los autores, el texto, los lectores en el «Quijote» de 1605, México, UNAM, 2002.

TORO, F. de, «Función del yo narrativo y del autor implícito. Don Quijote como deconstrucción de modelos narrativos», en Cervantes, su obra y su mundo, Actas del I Congreso Internacional sobre Cervantes, Madrid, EDI-6, 1981, pp. 635-651.

Torrente Ballester, G., El «Quijote» como juego y otros trabajos críticos, Madrid, Guadarrama, 1975.

VARIos, Cervantes, Alcalá de Henares: Centro de Estudios Cervantinos, 1995.

VARIOS, Releyendo el Quijote, cuatrocientos años después, dir. Agustín Redondo, Alcalá de Henares: Presses de la Sorbonne Nouvelle-Centro de Estudios Cervantinos, 2005.

Recibido: 25 de febrero de 2010

Aceptado: 7 de julio de 2010

\section{Resumen}

El objetivo de este artículo consiste en identificar la voz genuina del Cervantes creador en el coro múltiple de intermediarios ficticios involucrados en la autoría y en la narración del Quijote (cronista, editor, traductor, Cide Hamete, supernarrador, lectores, etc.), procurando, a la vez, calibrar el sentido y el alcance de sus intervenciones.

Ocurre que Miguel de Cervantes se reserva un papel novelesco radicalmente distinto según se trate de la «historia de la historia» o de la «historia en sí misma»: tratándose de la primera, el autor se queda fuera del reparto, delegando la reconstrucción de la leyenda quijotesca en múltiples máscaras ficticias siempre manipuladas cómicamente; por contra, cuando le toca el turno al diseño novelesco de las andanzas caballerescas de don Quijote y Sancho, la voz del Cervantes creador pasa a primer plano para asumir en solitario - como «autor definitivo» - toda la responsabilidad narrativa con absoluta omnisciencia y gravedad.

El Quijote resultante sólo puede explicarse desde la intersección de ambas actitudes: la historia risible de la más grave y grandiosa apuesta novelesca nunca ensayada.

Palabras clave: Cervantes, Quijote, narrador. 
Title: The voice of Cervantes «creator» in Don Quixote

\begin{abstract}
The aim of this paper is identifying the genuine voice of the Cervantes creator in the multiple choir of fictitious intermediaries involved in the authorship and the story of Don Quijote (reporter, editor, translator, Cide Hamete, supernarrator, readers, etc.) trying, at the same time, to gauging the sense and the scope of their interventions.

It happens that Miguel de Cervantes keeps to himself a novelistic role radically different depending on whether it is about the «story of story» or the «story itself»: refering to the first one, the author is out of the cast, delegating the reconstruction of Don Quixote's legend in multiple fictional masks always comically manipulated; on the other hand, when it is the turn to the novelistic design of the chivalrous adventures of Don Quixote and Sancho, the voice of Cervantes creator comes to the forefront in order to take on, - as the «final author»- all narrative responsibility with absolute omniscience and solemnity.

The resulting Quijote can only be explained from the intersection of both attitudes: the risible story of the most solemn/serious and magnificent novelistic bet never tried out..
\end{abstract}

Key words: Cervantes, Quijote, narrator. 